\title{
DIAGNÓSTICO LABORATORIAL DE VARIOLA. III - RESULTADOS DO TERCEIRO ANO DE ATIVIDADES *
}

\author{
J. A. Mesquita $* *$ e H. G. Schatzmayr $* * *$
}

Os autores apresentam os resultados obtidos no terceiro ano de atividades do laboratório de Diagnóstico de Variola, mo Instituto Presidente Castello Branco, ida Fundação Instituto Oswaldo Cruz, no Rio lde Janeiro.

O exame de 82 espécimens de crosta $e$ de 70 de líquido vesicular/pustular forneceu respectivamente 14 e 16 lamostras de virus da variola (Tabela 1).

Oriundos do Estado da Guanabara, foram examinados 33 espécimens $e$ isoladas 23 amostras de virus variólico (Tabela 2).

Foram comparadas as vacinas antivariólicas preparadas em ovos embrionados e as preparadas em pele de vitelos, tendo sido consideradas equivalentes nas condições descritas.

o laboratório continua a receber regularmente mais espécimens para diagnósticó.

As atividades da Campanha de Erradicação da Varíola (CEV) no Brasil têm evidenciado a importância do laboratório de diagnóstico.

Com a conclusão da fase de ataque da CEV em todo o território brasileiro (1), no primeiro semestre de 1971, inicia-se agora a fase de vigilância epidemiológica, em que o laboratório assume a grande responsabilidade de apoiar as operações de recobertura e bloqueio de casos esporádicos.

O presente trabalho relata os resultacos obtidos durante o terceiro ano de atividades no laboratório de Vírus Vesiculares e Exantemáticos do Instituto Presidente Castello Branco da Fundação Instituto Oswaldo Cruz sob os seguintes aspectos:
I - Exame de 152 espécimens coletados em diferentes estados do Brasil, através a CEV e serviços regionais de Saúde Pública Em nosso laboratório desde maio de 1969 , já foram examinados 423 espécimens, dos quais os primeiros 271 foram alvo de publicações anteriores $(5$ e 6$)$.

II - Análise estatística de uma comparação entre vacinas antivariólicas produzidas em ôvo embrionado e em vitelo, avaliadas por titulação de anticorpos inibidores da hemaglutinação em primovacinados.

\footnotetext{
( *) Trabalho do laboratório de Virus Vesiculares e Exantemáticos. Instituto Presidente Castello Branco, Fundaça Instituto Oswaldo Cruz, executado em parte com o auxilio do CNPq.

$(* *)$ Professor-Assistente, responsável pelo laboratório de virus vesiculares e exantemáticos.

(**) Professor-Titular, responsável pelos laboratórios de Vírus.

Enderếo Telegráfico: SAPÚBLICA, Caixa Postal 8016 - ZC-24. Rio de Janeiro - Brasil.

Recebido para publicaçăo em 17-9-71.
} 


\section{MATERIAL E MÉTODOS}

I - De 152 pacientes, foram examinados 82 espécimens de crostas e 70 de liquido vesicular/pustular.

Essencialmente, foram empregados os métodos de trabalho recomendados pela Organização Mundial da Saúde, com modificações descritas anteriormente $(3,5$ e 6$)$.

II -- A comparação entre as vacinas antivariólicas obedeceu a seguinte ordem cronológica de proceäimentos:

a) distribuição das vacinas produzidas no Instituto Oswaldo Cruz (V.A.V. - OL221 e V.A.V. - VL271), a dois Postos de Saúde, um na Tijuca e outro em Jacarepaguá em quantidades suficientes para que cada frasco de vacina aberto fôsse desprezado ao fim de cada um dia de uso.

b) uma coleta de sang̨ue, por punção venosa, das crianças ao serem vacinadas contra variola, nos postos citados. Incluiram-se no estudo 55 crianças no grupo etário de 5 a 22 meses. c) leitura de "pega" aos 7 dias da vacinação.

d) uma seguncia coleta de sangue um - mês após a vacinação.

No Laboratório congelaram-se as amostras de sôro à medida em que foram recebidas, sendo mantidas $a-20^{\circ} \mathrm{C}$ até o recebimento da $2^{\circ}$ coleta.

Procedeu-se à titulação de anticorpos por inibição da hemaglutinação em microtìtulação como anteriormente descrito (2 e 4).

Os resultados sorológicos da primeira e segunda coletas foram pareados, e procedeu-se à análise estatística comparativa dos títulos de anticorpos circulantes encontrados.

\section{RESULTADOS}

I - De 152 espécimens examinadas, 30 amostras de vírus da variola foram isoladas em ovos embrionados e identificadas sorològicamente por precipitação em agar-gel.

As taxas de isolamento alcançaram $17 \%$ e $23 \%$, respectivámente para espécimens de crostas e de líquido vesicular/ pustular (Tabela 1).

T A B E L A 1

NATUREZA DOS ESPÉCIMENS E RESULTADOS LABORATORIAIS

\begin{tabular}{l|c|c|c}
\hline \multicolumn{1}{c|}{$\begin{array}{c}\text { NATUREZA DOS } \\
\text { ESPECIMENS }\end{array}$} & $\begin{array}{c}\text { RESULTADO } \\
\text { VARIOLA }\end{array}$ & $\begin{array}{c}\text { RESULTADO } \\
\text { NEGATIVO }\end{array}$ & $\begin{array}{c}\text { TOTAL DE } \\
\text { EXAMES }\end{array}$ \\
\hline Crostas & $14(17 \%)$ & 68 & 82 \\
Liquido Vesicular/Pustular & $16(23 \%)$ & 54 & 70 \\
\hline
\end{tabular}


No Estado da Guanabara foram isoladas 23 amostras de virus da variola, dentre 33 espécimens examinados no período íTabela 2).

T A B E L A 2

\section{ORIGEM DOS ESPECCIMENS EXAMINADOS \\ E AMOSTRAS DE VARIOLA ISOLADA POR ESTADOS DA FEDERAÇÃO}

\begin{tabular}{l|r|r}
\hline \multicolumn{1}{c|}{ E S T A D O S } & $\begin{array}{r}\text { Espéci- } \\
\text { mens } \\
\text { exami- } \\
\text { nados }\end{array}$ & $\begin{array}{c}\text { Amos- } \\
\text { tras de } \\
\text { varío- } \\
\text { la }\end{array}$ \\
\hline & & \\
\hline Guanabara & 33 & 23 \\
Bahia & 29 & 3 \\
Espírito Santo & 28 & - \\
Ceará & 20 & - \\
Pernambuco & 18 & - \\
Sergipe & 9 & 3 \\
Rio de Janeiro & 6 & - \\
Distrito Federal & 3 & 1 \\
Maranhão & 2 & - \\
Alagoas & 1 & - \\
Amazonas & 1 & - \\
Minas Gerais & 1 & - \\
Paraíba & 1 & - \\
& & \\
\hline \multicolumn{1}{c}{ Totals } & 152 & 30 \\
\hline
\end{tabular}

II - Todos os casos apresentaram leitura positiva de "pega". Todos apresentaram sôro-conversão, isto é, deram resultado de HI 1:10 na primeira coleta e titulos que variaram entre HI 1:10 e 1:640 (Tabela 3).

O título geométrico médio de anticorpos detectados por inibição da hemaglutinação, foi de $1: 57,61 \mathrm{pa}-$ ra 0 grupo que recebeu V.A.V.-0L221 e de 1:94,17 para o grupo que recebeu V.A.V.-VL271.
T A B E L A 3

TÍTULOS IH E TGM OBTIDOS 30 DIAS APÓS A PRIMOVACINAC̣ÃO ANTIVARIÓLICA COM VAV-0L221 E VAV-VL271

\begin{tabular}{l|c|c}
\hline TITULOS IH & VAV-0L221 & VAV-VL271 \\
\hline $1: 10$ & 2 & - \\
$1: 20$ & 8 & 2 \\
$1: 40$ & 5 & 2 \\
$1: 80$ & 17 & 5 \\
$1: 160$ & 4 & 7 \\
$1: 320$ & 1 & 1 \\
$1: 640$ & 1 & 17 \\
\hline Vacinações & 38 & \\
\hline - & & \\
\hline T.G.M. & $1: 57,61$ & $1: 94,17$ \\
\hline
\end{tabular}

Tit. $\mathrm{IH}=$ Titulo de anticorpos inibidores da hemaglutinação.

TGM = Título geométrico médio calculado a partir dos títulos IH.

VAV-0L221 = Vacina antivariólica produzida em ôvo embrionado, lote 221.

VAV-VL271 = Vacina antivariólica produzida em vitelo, lote 271 .

\section{DISCUSSÃO}

I - A taxa cie isolamento de vírus a partir de espécimens de líquido vesicular/pustular maior que de espécimens de crostas (Tabela 1), deve ser interpretada considerando-se que a maioria dos espécimens de líquido vesicular/pustular foi oriunda de áreas próximas ao laboratório, demorando menor tempo entre a coleta e oxame.

O isolamento de vinte e três amostras, dentre os trinta e três espécimens recebidos do Estado da Guanabara (Tabela 2), reforça o comentário do período anterior. Seis dessas amostras foram isoladas entre fevereiro e abril de 1971, e completam, com outras treze amostras não recebidas em 
nosso laboratório, os únicos 19 casos notificados à CEV até junho dêste ano no Brasil (2).

$$
\begin{aligned}
& \text { II - Como o título geométrico médio } \\
& \text { (T.G.M.) dos anticorpos de primo- } \\
& \text { vacinados, detectados por inibição } \\
& \text { da hemaglutinação foi mais baixo } \\
& \text { para o grupo que recebeu VAV- } \\
& \text { - 0L221 (TGM }=1: 57,61 \text { ), do que } \\
& \text { para o grupo que recebeu VAV- } \\
& \text {-VL271 (TGM }=1: 94,17 \text { ), foi apli- } \\
& \text { cado o teste de diferença de mé- } \\
& \text { dias, o que resultou T calc/ }= \\
& =1,96137 \text { contra T TAB }=2,0003 \\
& \text { ao nível de significância de } \ldots \\
& \alpha=0,05 \text {. }
\end{aligned}
$$

Como $T$ calc/ $<T$ TAB, conclui-se que não existe diferença significativa no título médio entre os dois atributos.
Considerando os resultados da análise estatística, além de que tôdas as vacinações estudadas correspondem a "pega" e soroconversão, podemos considerar como equivalentes os resultados obtidos com os dois tipos de vacinação antivariólica empregados, nas condições descritas.

Estes dados apesar das naturais dificuldades encontradas para se obter um maior número de crianças, parecem-nos importantes em nosso meio de vez que as vacinas antivariólicas em ôvo embrionado são preparadas e empregacias em larga escala no nosso País.

\section{AGRADECIMENTOS}

Os autores agradecem ao laboratorista Ismael da Rocha Lopes pela excelente assistência técnica prestada.

The authors present the results which have been obtained during the third year of work in a Smallpox Diagnosis Laboratory unit set up to support the National Smallpox Eradication Compaign in Brazil.

The examination of 82 crusts and 70 vesicular/pustular fluid specimens resulted in the isolation of 14 and 16 smallpox strains respectively (Table 1 ).

The examination of 32 specimens from Guanabara state. resulted in the isolation of 23 smallpox strains (Table 2).

Both vaccines prepared on embrionated hen eggs and prepared on calf skin have been comparea and results were similar in the described conditions.

The laboratory is getting regularly more specimens for diagnosis.

\section{BIBLIOGRAFIA}

1 - Boletim da C.E.V., tomo 5 no 19 , págs. 1 e 3,1971 .

2 - Boletim da C.E.V., tomo 5 no 17, pág. 7, 1971 .

3 - Guide to the laboratory diagnosis of smallpox, World Health Organization, Geneva, 1969

4 - HIERHOLZER, J.C., SUGGS, M.T. \& HALL, E.C. - Standardized viral hemagglutination and hemagglutination-inhibition tests - I and II, appl. Microbiol.; 18:816-833, 1969.
5 - SCHATZMAYR, H.G. \& MESQUITA, J.A. - Diagnóstico laboratorial de varíola. I - Resultados do primeiro ano de atividades, Rev. Soc. Bras. Med. Trop. IV: 355-359, 1970.

6 - SCHATZMAYR, H.G. \& MESQUITA, J.A. - Diagnóstico laboratorial de variola. II - Resultados do segundo ano de atividades, Rev. Soc. Bras. Med. Trop. IV: 371-375, 1970.

7 - SEVER, J.L. - Application of a microtechnique to viral serological investigations. J. Immunol. 88: 320-329, 1962 . 